\title{
Advanced Life Support: evolution of resuscitation practices in France between 2012 and 2018
}

Valentine Baert ${ }^{1,2}$, Joséphine Escutnaire ${ }^{1,2}$; Manon Santerne ${ }^{1,2}$; Christian Vilhelm ${ }^{1,2}$; Karim Tazarourte ${ }^{2,3}$; Carlos El khoury4; Hervé Hubert ${ }^{1,2}$ and on behalf GR-RéAC.

Purpose of the study: The French emergency system follow the "stay and play" model. This system is two-tiered with a prompt intervention provided by firefighters and the advanced life support (ALS) by mobile medical team (MMT). MMT follow international guidelines for out-of-hospital cardiac arrest care. This study aim was to describe ALS in France between 2012 and 2018.

Materials and methods: The French national OHCA registry recorded 62,474 medical OHCA adult victims between 01/01/12 and 09/01/18.

\section{Type of intubation}

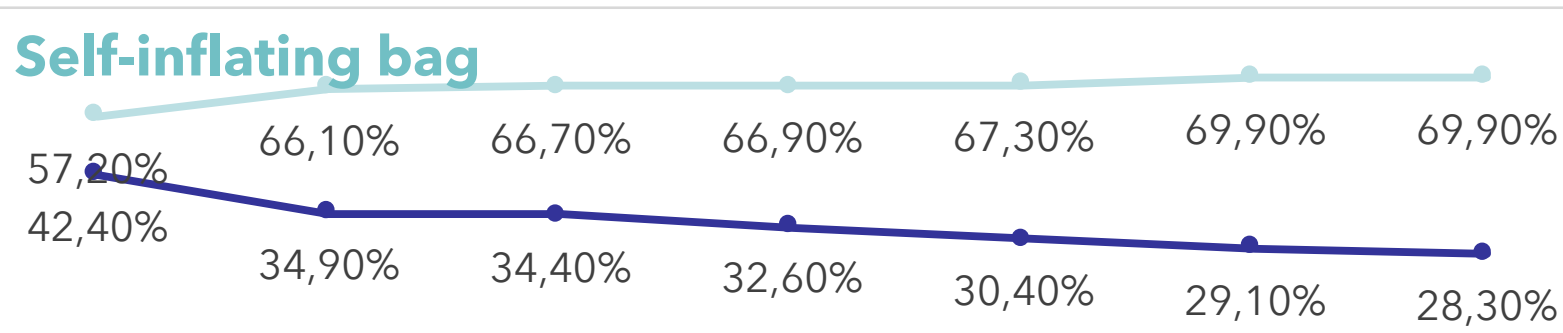

Assisted controlled volume

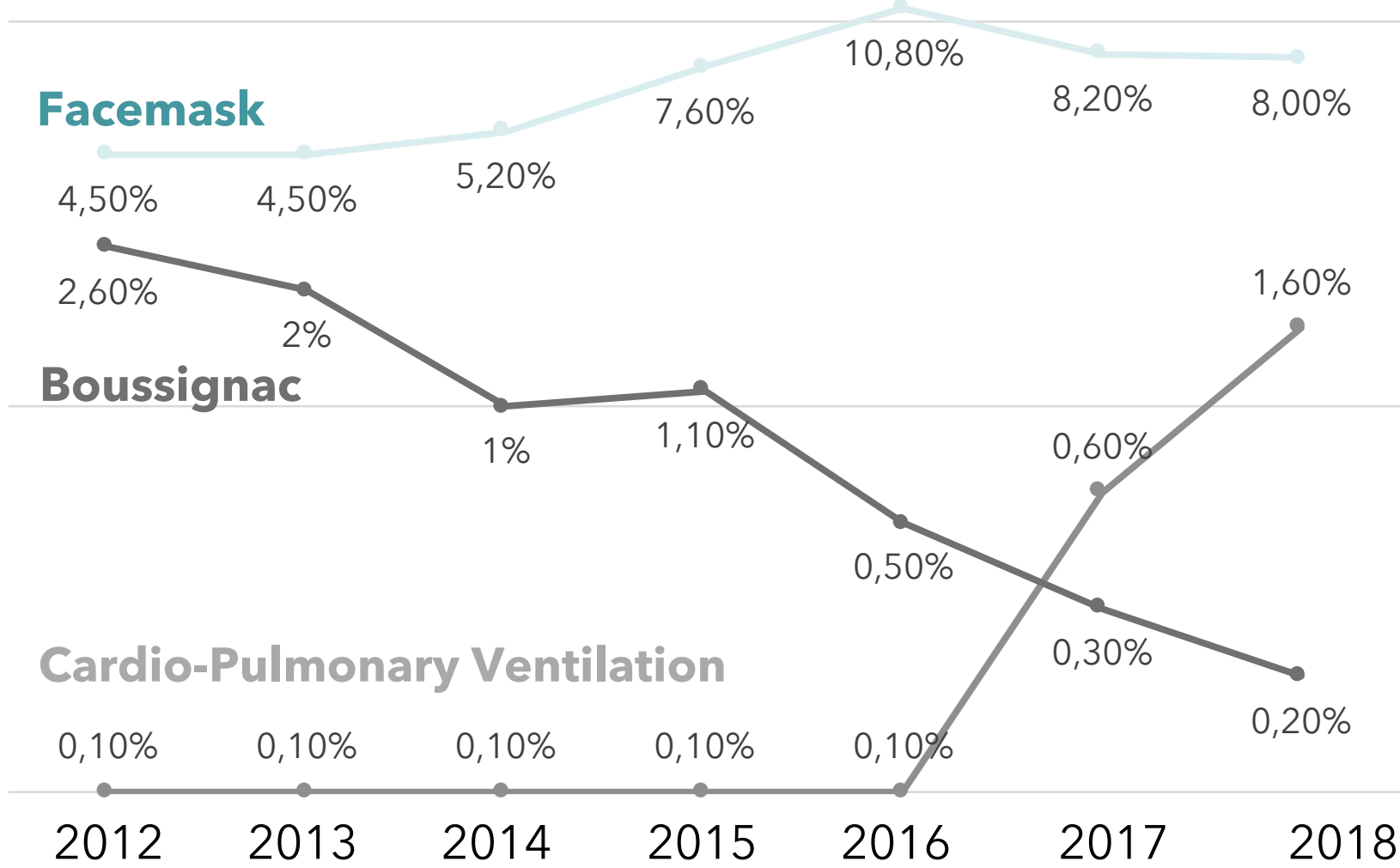

\section{Type of injection route}

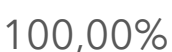

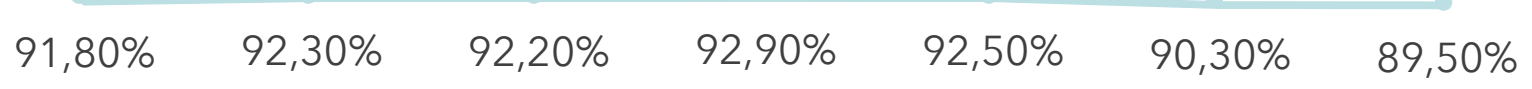

Peripheral venous acces
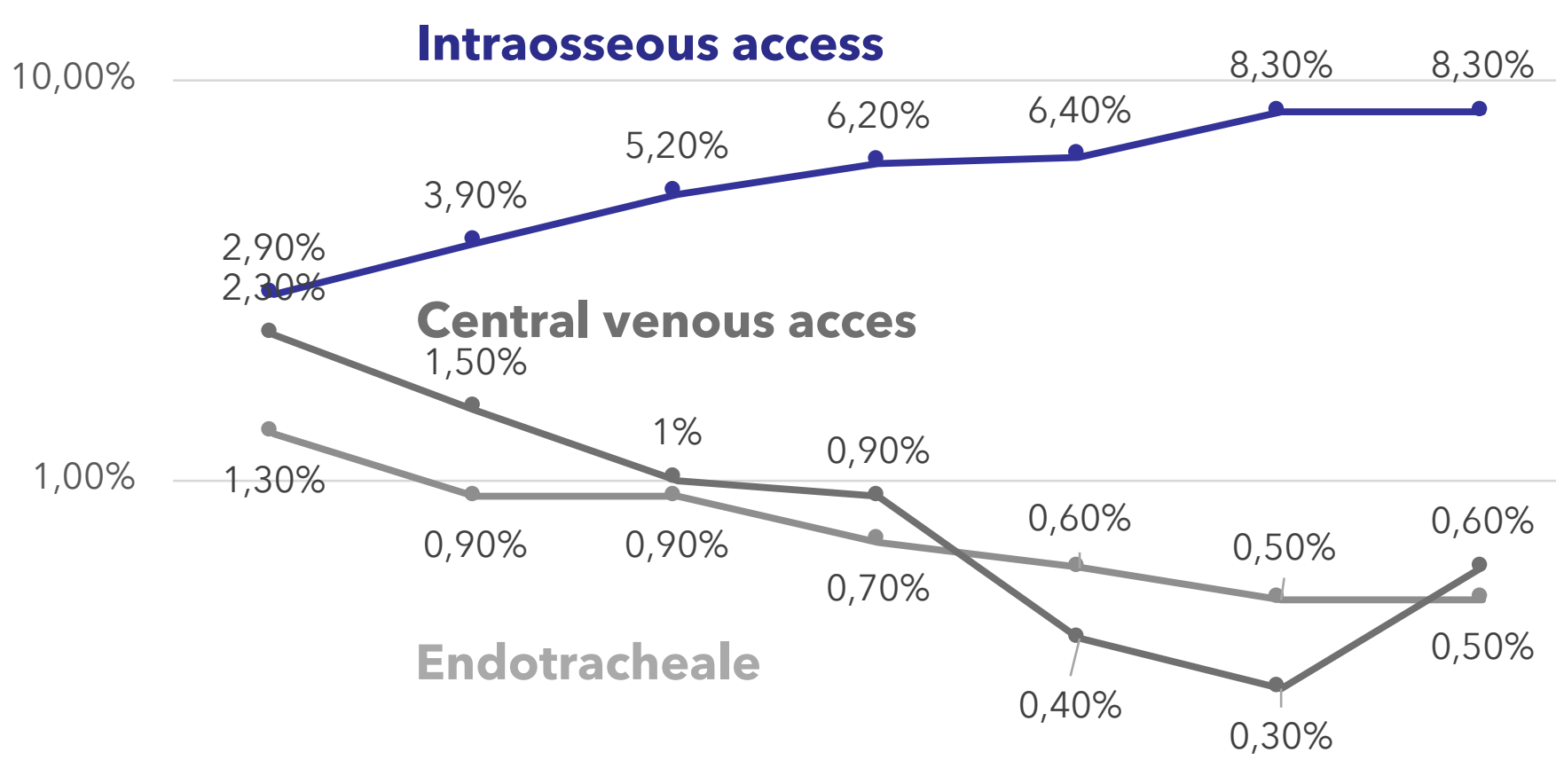

$0,10 \%$

$2012 \quad 2013 \quad 2014 \quad 2015 \quad 2016 \quad 2017$

Results: In France, $72.5 \%$ of victims were resuscitated by MMT. Regarding drug strategies, for patients with a shockable rhythm, epinephrine and amiodarone were consistently used over the years (respectively $86.9 \%$ and $68.7 \%$ ). Adrenaline and amiodarone median doses were $6 \mathrm{mg}$ and $300 \mathrm{mg}$ per treatment. The use of other drugs: fibrinolytics, aspirin, bicarbonates and atropine, decreased between 2012 and 2018. Regarding nonshockable rhythms, the use of adrenaline and fibrinolytics was constant (respectively $92.6 \%$ and $2.4 \%$ ). The median dose of epinephrine by patient was $5 \mathrm{mg}$. Amiodarone, aspirin, bicarbonates and atropine use decreased between 2012 and 2018.

Conclusions: We still report endotracheal and central venous uses as well as atropine injections. The intraosseous route is more and more used. In France, ALS guidelines are generally respected. 